\title{
Finding Sociality in Single Player Games: A Case Study of Tandem Play Amongst Friends and Couples
}

\author{
Mia Consalvo \\ Concordia University \\ mia.consalvo@concordia.ca \\ Sarah Ganzon \\ Concordia University \\ scvganzon@gmail.com
}

\author{
Jason Begy \\ Concordia University \\ jsbegy@alumni.mit.edu \\ Rainforest Scully-Blaker \\ University of California Irvine \\ fscullyblaker@gmail.com
}

\author{
Pierson Browne \\ University of Waterloo \\ pbrowne88@gmail.com \\ Rebecca Waldie \\ Concordia University \\ rwaldie@uwo.ca
}

\begin{abstract}
Researchers have found that games are sites for rich forms of sociality. However, there has been comparatively less research on sociality facilitated by co-located gameplay focused on single-player games, here termed tandem play. This exploratory case study investigated how known player pairs engaged in turn taking and decision-making behaviors while playing a single-player game together, and also how a narrativedriven video game played over multiple sessions impacted their experience. Initial findings suggest that turn taking was an explicitly negotiated choice, and that decision making power did not necessarily rely on who was holding the controller - player pairs developed their own systems for how they made choices. The narrative and well-known franchise on which the game was based gave pairs a strong base from which to work, building themed playthroughs and systemic approaches for how to treat various characters and situations in game. This research provides further evidence that being social in and around games can be accomplished no matter whether the chosen game is a single or a multiplayer title, and in virtual or physical space.
\end{abstract}

\section{Introduction - Sociality and play}

Countering the persistent myth of the antisocial, lonely video game player, researchers working across multiple disciplines have found that games are sites for rich and varied forms of sociality, particularly multiplayer games in virtual spaces [1]-[4]. However, there has been comparatively less research on sociality facilitated by co-located gameplay focused on singleplayer games [5].

Researchers studying individuals who play co- located multiplayer physical-based controller games such as Gajadhar, de Kort and IJsselsteijn find that physical play settings embody a "complex mix of social (with friends vs. with strangers), spatial (at home vs. at the Internet café) and media (side-by-side vs. online) characteristics" [6]. In their study with Dutch students they found that more aggression was reported among friends than among strangers, suggesting "perhaps play among friends is more intense than among strangers" $[6, p .116]$ and more importantly that more fun was "experienced when players were in the same room, than when they were apart" [p. 115].

Further supporting the claim that co-located gaming can be a social activity, a study of 36 individuals that gathered together regularly to engage in group console gaming by Voida and Greenberg found that "the primary motivation for group console gaming was not the games, themselves, but the social interactions afforded by the collocated gameplay" [7]. As part of that activity, they argue "sharing in the gaming experience may mean sharing in other activities related to the games and not necessarily the games, themselves." Yet the majority of the groups they studied chose multiplayer games from those available to them, with only one group choosing one or two-player games so that "the rest of the group could play along with the 'official' players. Interestingly, this group valued games in which audience members could take on active roles in gaming" [10, p. 1564].

Downs, Vetere and Howard have also investigated physical console gaming amongst groups in home settings in order to explore how playfulness occurred in multiplayer gaming sessions "even from those who were not actively participating in the game" [8]. They identified two distinct roles that participants took on - active player and audience member. As players assumed those roles, as well as transitioned between them, "various types of playful behavior 
emerge" [12, p. 697].

Importantly, they point out that such behaviors are "both enabled and mediated by factors such as the game's design, the gaming technology, pre-existing social relationships, and the superlusory goals of the session" [12, p. 697]. Downs et al have also argued that "rather than viewing individuals merely as players or non-players, there are a variety of different types of roles and opportunities for participating in different ways" [9]. They point to how different individuals present could act as coaches, hecklers, cheerleaders, commentators or spectators at different points throughout a game. Due to those multiple roles and activities, they concluded that the 'active player' or the person holding the controller "was no longer the sole controller of the gameplay any more than they controlled the physical game space" [13, p. 98]. Yet the games chosen for their study were all Kinectenabled and facilitated multi-player use, limiting our ability to generalize to other situations.

Related research on physical-controller based gameplay has theorized how players respond to and utilize both player space (their physical environment) and the screen space of the game (what they see via the monitor/television). Jesper Juul makes a distinction between "3-D space," "screen space," and "player space" [10, p. 17]. "3-D space" describes the virtual space created by a three-dimensional game that is perceived as extending into or beyond a screen. Twodimensional games exist in "screen space," which is defined by the physical bounds of the screen. "Player space" is the space in front of the screen and occupied by the players. To play games such as Dance Dance Revolution, Wii Bowling and Rock Band players necessarily create a spectacle in player space through their (often exaggerated) physical movements.

These are examples of what Juul calls "mimetic interface games," that is, games that "encourage interaction between players in player space, and in such a way that player space and 3-D space appear continuous" [16, p. 18]. Juul argues that the success of these games is due to the fact that mimetic interfaces move the focus of play to the player space, which makes them easier to learn while simultaneously creating new types of fun: "failure becomes an enjoyable spectacle, and [...] the games thereby become more immediately social than those played with standard game controllers" [16, p. 103]. Bogost has made a similar observation regarding Wii Bowling: "[...] it's common for players to converse and visit with one another while they await their turn. [...] that pattern of play bears much in common with traditional bowling" [11, p. 61]. In mimetic interface games and real bowling alike, the focus of the activity is the social aspect, not the game itself. Mimetic interface games de-emphasize the 3-D space and screen space as sources of pleasure in favor of player space, creating a kind of social experience common in our broader social lives. This lowers the barrier to entry for these games because they have more in common with traditional social activities.

\section{Social Television Viewing}

Another useful avenue for understanding sociality in group settings is through examining how groups watch television together. In a study of 'social television,' researchers had groups of 5-8 viewers watch TV together and studied how they interacted [12]. While Oehlberg et al found that the content they selected for viewing did make a difference on the levels of social interaction, there were clearly discernable interaction rules that participants respected, even though "these rules were never openly discussed by the participants" [15, p. 3]. Participants were also "particularly adept at predicting gaps in dialogues and transitions between scenes, in order to use these gaps to comment on the program" they were viewing [15, p. 4]. Similar to the roles found by Voida and Greenburg, Oehlberg et al found that viewers helped one another, such as when, during lulls in programming, newcomers are caught up on "what happened and is currently going on in a program" [15, p. 5]. Oehlberg et al conclude "interactions between television viewers are tightly interwoven with the structure of the show they are watching. ... the show itself has to be structured such that opportunities for communication exist" [15].

\section{Playing single-player games socially}

The research described above on co-located gameplay focuses on multiplayer games and does not explore the impact of single-player games on the act of play and sociality in groups. Likewise, most of the games investigated rely on (and indeed focus exclusively on) motion-controls, and also feature relatively short play sessions, such as Wii Sports and Rock Band. Further, such games often feature little or no story that would push players to continue playing the games over multiple sessions to discover, nor do they feature moral or ethical choices that might significantly affect game or story outcomes. Lacking such elements, there is little potentially invested by players in the outcomes of the games (beyond winning or losing) as well as from one session to another.

Initial work investigating those gaps has explored how pairs of players engage with single-player games and each other socially [13]. It has labeled this type of activity "tandem play," defined as "when two or more players engage with a single-player game together, 
moving through the game with a variety of potential motives" [13]. More specifically, tandem play refers to the joint, cooperative play of a single-player video game, such as occurs when friends pass a controller back and forth. Prior research has found that players easily engaged in turn-taking behaviors to share the game's controller and decision-making, that more experienced players often acted as 'tour guides' for players newer to the game, and that the game selected for the study (Dragon Age: Inquisition) had particular impacts on the findings. Yet that work was mostly focused on pairs who did not know one another prior to the study. Further, the game used in the study led to surprisingly little investment by players in making story-related decisions within the game, due to its length relative to the length of the study. To address those shortcomings this paper reports on an exploratory case study that further refines the concept of tandem play. In doing so it also investigates the linkages between tandem play and social TV viewing, and challenges the player/spectator and player space/screen space dichotomies that much game research perpetuates.

\section{Methods}

Because this research is exploratory the study focuses on only three research questions:

RQ1: "How (if at all) do known player pairs engage in turn taking behaviors when playing a single-player video game together?"

RQ2: "How (if at all) do known player pairs engage in decision-making behaviors regarding gameplay when playing a single-player video game together?"

RQ3: "How (if at all) does a narrative-driven game played over multiple sessions impact how player pairs interact with one another when playing a single-player video game together?"

To study that behavior, Game of Thrones: $A$ Telltale Game Series (GoT) was selected as the game for pairs to play. GoT is an episodic adventure game that builds on the story of George R.R. Martin's Westeros universe. It features several playable characters and a storyline parallel to the main plotlines in the novels and the television show. The game was created by developer Telltale Games, and six episodes were released for multiple platforms over a period of almost a year, beginning in December 2014 and concluding with episode 6 in November 2015. Each episode takes approximately 2-3 hours to complete, and most of the game focuses on exploration, moral decision-making, and successfully completing some Quick Time Events. This game was chosen for several reasons. It is a single player game that was popular at the time of the research (the final episode came out during our study), which we hoped would be a draw for potential participants. The game features many key decision points and has both a slow pace allowing time for socialization, and some timed dilemmas that we thought might push pairs to debate actions and consequences more urgently. Finally, it was a short enough game for subject pairs to potentially finish in a reasonable period of time.

Subjects were recruited via social media and word of mouth to participate in this study. We were specifically interested in friends or couples, which we highlighted in recruiting efforts. We recruited two subject pairs to engage in the research - one pair was a married couple and the other pair were good friends.

Each pair was asked to play at least the first three episodes of GoT together (with the option to play more if they desired), with no guidelines given over how to do so. They sat together on a couch in Concordia University's mLab and played on an Xbox One via a single standard controller. All in-game decisions, such as what to do, where to go, and how to respond in conversations, were made by the subject-pairs, who also decided when and if to pass the controller between them. Meanwhile, researchers sat off to the sides of the couch (also facing the TV) to observe and take field notes, and answer questions as needed. Researchers observed turn taking behavior, spatial positioning of the pairs over time, their behaviors relative to each other and the game, and also took notes on their conversation - recording key dialogue- as well as their nonverbal communication. One research also had a checklist for each episode to record the important choices that the pairs took, who took them, and if they failed to make a choice in a timed event.

The friend-pair (Miranda and Rose ${ }^{1}$ ) played all six episodes of the game together for approximately twelve hours, while the couple (Emiko and Michael) played the first three episodes during our study, for approximately 6-7 hours of total gameplay. After each pair's final play session two researchers conducted semi-standardized exit interviews with each subject individually. Question order naturally fluctuated somewhat as we conducted our interviews in a conversational manner. The interview questions covered three topics: demographics, how the subject liked the game, and how they collaborated with their partner. We also asked about their play habits and game interests more generally, and how they might have played the game if they had done so on their own.

\footnotetext{
${ }^{1}$ All names used are pseudonyms.
} 
Finally we encouraged subjects to speak freely about their experiences in the study.

\section{Findings: Friends and Couples Playing Together}

This study was focused on how pairs with prior histories together would play a single player game in tandem. Our observations showed (and participants later confirmed in interviews) that both pairs were very comfortable interacting with one another, evident in their relaxed conversational styles, references to shared past histories, and their body language. Past research on tandem play found that pairs were generally polite in ensuring that both players took turns holding and using the controller, but that they did not engage in any explicit negotiations about how or how often to take turns. To determine if known pairs would be different, our first research question asked "how (if at all) do known player pairs engage in turn taking behaviors when playing a single-player video game together?" We found that each pair had a different strategy for managing the controller during their sessions. In 5 of the 6 sessions Miranda and Rose passed the controller back and forth when characters changed so that each person would have roughly equal time with the controller (more on their outlier session later). Emiko and Michael took a very different approach - Michael alone held the controller and manipulated events on screen (including fighting and making choices) while Emiko directed his actions in extensive detail.

As prior research has found, holding the controller meant having the power to do multiple things in the game [13]. In a game such as GoT this meant engaging in the (somewhat limited) Quick Time Events (QTEs) for battles and some actions, driving characters around scenes, and - the major part directing the choices that the various characters would make in each episode.

Our second research question asked "How (if at all) do known player pairs engage in decision-making behaviors regarding gameplay when playing a singleplayer video game together?" Prior research found that amongst pairs who did not know each other well, individuals were again polite and would usually consult their partner about decisions, particularly if it was a major one such as in avatar creation or a storyrelated decision [13]. With GoT pairs in observations we witnessed far more extensive discussions and debates about what to do at particular moments in the game. Our notes show both pairs actively conferring with one another as well as pausing the game at different times to make sure they had the input of their partner before continuing - particularly during important choices in the game. In the case of Emiko and Michael, if they had a disagreement about what to do, Emiko's choice would prevail, as it was decided in advance that this was her playthrough of the game. For Rose and Miranda there were only a few times when they ultimately agreed to disagree on what to do in the game. During episode 6 the character Mira Forrester is given the option of keeping or burning the agreement she made with Tyrion about selling her family's lumber, after it has been shown that Tyrion is (supposedly) the traitor that killed King Joffrey. Even though Rose was holding the controller she paused and asked Miranda what she wanted to do. Miranda advocated burning the letter and even though Rose disagreed, she still carried out Miranda's wish. During her interview Rose confirmed that she didn't "push back" against Miranda's decision and in the end "it worked in our favor, we didn't get tied in with Tyrion." She emphasized that she still disagreed at the time, but made no further claims as to why she made a choice that she ultimately did not support. Our findings also confirmed that even when a game tries to make particular choices feel 'urgent' for players, such as through giving them a timed option for a choice, players will exert agency over the game in order to 'make time' for their own decision making processes. Thus, we witnessed both pairs regularly pausing the game during timed choices, thwarting the games' (and our interests in) making particular events feel pressing or more important than others.

Our third research question sought to investigate how a strongly narrative-driven game that unfolded over multiple episodes (and therefore game sessions) would impact how player pairs interacted with one another and also how it affected their gameplay. Relatedly, but not part of the explicit research question, was our interest in seeing if a game with less action/exploration and more talking might change how pairs played as well as socialized around and about the game, in line with research about social tv viewing.

GoT was a good choice in this regard, as the story and characterizations offered pairs rich material from which to draw for potential sociality. The pairs had the option to finish the entire season, and they did take their playthroughs more seriously than prior research pairs did, at least in terms of determining a 'style' or theme for their playthrough of the episodes. It should also be noted that all four GoT participants had seen and/or played two of the six episodes prior to our study, but they all witnessed newer (to them) episodes as well. Miranda and Rose had determined for their sessions to have a 'sassy' playthrough (their term), which also evolved into a 'dick playthrough' according to both of them. Our fieldnotes also show them discussing which characters they liked and disliked during their first few gameplay sessions, and how to play them. During their first episode, in response to a 
dilemma about how to play Mira Forrester, Rose asked Miranda "Do we want to save our family? Or fuck that" to which Miranda replied "We have a position here. Fuck that!" Miranda and Rose also decided they didn't like the character Sera (a friend to Mira, both of whom are handmaidens to Margaery Tyrell in King's Landing) and often shouted "Fuck you Sera!" whenever she appeared on screen. The first significant debate they had as a pair was during the last episode, over the extent to which they wanted to 'throw Sera under the bus' - with both ultimately deciding to go as far as the game would allow.

While they were somewhat quieter than Miranda and Rose (who talked almost non-stop during their sessions to/about/at the game, to each other, and to other people present), Emiko and Michael also discussed how to play the game, but in a very different way. As Emiko explained in her interview, the couple has a unique play style, which they developed on their own before our sessions, when Emiko wanted to play Mass Effect but didn't have the skills to get through the entire game series on her own. In contrast Michael had more gameplay experience and they developed a system where Emiko would "make all of the decisions" while Michael would hold the controller and carry out her commands. As Emiko put it, "he's just kind of like acting as my physical avatar to make those things happen." She is also careful to distinguish that Michael will often play through a game first on his own, which is considered his playthrough by the couple, while the tandem sessions are usually her playthroughs, so that "I get to make the decisions, I pick what piece of furniture to look at first in a room, I pick which dialogue options" and Michael "does any of the Quick Time Events." This was quickly evident during their sessions, as Emiko would often be sitting physically close to Michael, verbally prompting him on how to proceed. For bigger decisions that required some thought, Michael on many occasions would pause the game so they could discuss which choice to make. But even though Emiko explained their playthrough as one where her decisions were paramount, we did see Michael exerting some agency beyond pushing appropriate buttons or executing a QTE. Sometimes this meant supporting or further justifying a choice that Emiko made, or it could mean reminding her of what she had done before - either in prior episodes or prior playthroughs of the game.

For example, during the first episode when the player as Garret is faced with the choice of whether or not to kill two men who have just killed his family, Michael drew the character's sword and proclaimed "I am going to kill you all because I'm awesome with the right stick." Emiko jumped in "But I want to be pacifist this time." However, Michael pointed out to her that
"You were a pacifist last time," implying that they/she had wanted to do a different kind of playthrough this time through. Yet during the attack Emiko still decided to let the second man escape, to which Michael reacted "What?!" but chose that option anyway. As if to justify her choice, which would appear to mimic what she did in her prior playthrough of the scene, Emiko said in response to Michael that "It's a shitty situation either way."

Michael also helped to justify Emiko's choices by pointing to how they might still support the narrative arc she was building. During Episode 3 in a conversation between Mira and Sera, Emiko chose a 'trusting and supportive' response for Mira. Michael made the choice for her - but responded in a way that both echoed his own thoughts on the situation and bolstered Emiko's larger playthrough goals. He started out by saying "I would have been tough. NOTHING COMES FOR FREE." Emiko responded "oh right! We're playing her as a cold schemer this time," to which Michael answered by reaffirming her choice: "Yeah, but she still needs friends. This is fine." In addition to showing how the pair negotiated Michael's sometimes differing opinions as well as how he often would try to 'make the story' fit their desired actions, this sequence also demonstrates how Emiko and Michael also developed particular personas or favored interaction styles the main characters in the game, just as Miranda and Rose did.

Contrary to the stranger pairs studied in prior work, the comfort that known pairs had with each other extended to occasional mild admonitions and chiding of each other. This could include gentle naggings, where one partner wanted to refocus attention back on the game when their partner's attention had strayed something not reported on with respect to strangers, who were unlikely to comment if their partner decided to go to the bathroom, take a call, or eat dinner during their play sessions [13]. While we did see many instances were such actions were similarly unremarked on (particularly the checking of phones), there were other times when one person would call out their partner and request that their attention be returned to gameplay. For example, during their second session Rose in particular was quite tired, and moved around restlessly during the session. At one point she attempted to lie down on the floor and Miranda pinched her, exclaiming "Noo! Don't go to sleep! I need your help!" In response Rose sat on the floor in front of the couch, but soon after that she leaned back against the couch and after a few more minutes we observed her playing her turn with the controller while laying down. During all their play sessions together, the two easily moved around the space and each other, sitting up, laying down, feet up or on the couch, using 
the couch and nearby beanbag chairs from which to play. In contrast Michael and Emiko mostly stayed on the couch during their sessions, although during their third (and final) session Emiko brought her knitting along with her- something that she says she often does when the pair play together at home. Most of the time this didn't impede her play, as we noticed her eyes regularly flitting back and forth from her knitting to the game screen. At the beginning of the session Michael told Emiko to put away her knitting for our "scientific study." We told them it was fine if Emiko wanted to knit. Michael explained that this was how they usually played, but it meant that sometimes they missed conversations in the game due to her divided attention. In a prior session Michael had also chastised Emiko for picking up her phone at one point, stating "Emiko, this is for science!" to which she just laughed.

\section{Social Viewing/Gaming in Player Space}

The narrative of GoT was related to a transmedia world that our pairs already were familiar with based on prior knowledge of the novels and television show of the same name. This knowledge, along with the familiarity of the pairs to each other, combined to form a rich opportunity for sociality. With both pairs we witnessed this occurring with discussion, debates, exclamations, and jokes about the options and choices offered by Game of Thrones writ large. With the game chosen, players rarely had extensive control over the characters or the game world. As a result, the social aspect shifted: subjects put more effort into discussing (and mocking) the game, and emphasis generally shifted from the screen space to the player space as players talked to each other more directly, as opposed to using the game as a medium for performance [10]. For example, Michael would often mimic certain characters' speech, putting on exaggerated accents to draw laughs from Emiko and the researchers. Rose once compared Lady Forrester to Lieutenant Uhura from Star Trek, and both Miranda and Rose during their fourth session began rating and judging characters based on whether or not they had a 'bowl-style' of haircut: determining that "everyone" with a bowl-cut will inevitably betray them/as protagonists.

In this way the overall effect for both pairs was closer to watching television together than basic game exploration, although both pairs did take pleasure in the interactive parts of the game. But what this shows is that mimetic interface games are not the only type of game that leads to an emphasis on player space: linear games with a low degree of interactivity can do so as well.

\section{Giving you license to be bad? Tandem Playing as Mean and Sassy}

Our case study is obviously not representative of all players, but we noticed some interesting phenomena in our observations that warrant more in-depth research into how individuals respond to moral dilemmas in games when they are playing with other people. Prior research on tandem play did not explore this question, largely because the game chosen does not have any strong moral dilemmas in its early gameplay. But research by other scholars has shown that a majority of players tend to choose the side of 'good' or to play as 'better versions of themselves' during single-player games that feature moral choices [14], [15].

The two playthroughs we witnessed were decidedly 'meaner' than what that evidence would suggest. As mentioned above, Rose and Miranda had decided early on to create a 'sassy' playthrough that they alternatively referred to as 'the dick playthrough' throughout their play sessions. Emiko and Michael were also fairly tough on the characters, although we only saw them play three episodes, and the pair's choices were also affected by their/Emiko's wish to play things differently than she had in her first playthrough of the game, which happened before the study began.

For example, both pairs agreed in the first episode when young Ethan Forrester is confronted with a choice of how to punish a thief (send him to The Wall; chop off three of his fingers; or let him go) to take three fingers, with Michael stating "I was ready to chop off his head" and Miranda and Rose showing no hesitation in choosing the same option. Both pairs also commented often on how unsympathetic they were being in how they made decisions. At one point in the first episode Michael conceded, "I feel like in this playthrough we deserve to be stabbed." Similarly at the start of the second episode Rose reminds Miranda of how they agreed to play, asking rhetorically "I thought we are being dicks to everybody?"

Both pairs expressed this intention in multiple ways throughout their play sessions, although their actions were not always consistent with their stated intents. Mostly they enjoyed being mean to certain NPCs (Sera was a popular -unpopular choice) and choosing violent and sneaky options when they were available. Both pairs as Mira chose to steal the official family seal that Margaery Tyrell had left out on a table, despite there being no immediate use for the item until later in the game when it became relevant. Miranda and Rose in particular took great delight in one scene where they chose to throw an axe at Lord Whitehill's face and started a melee that ended in a game over 
screen, which Rose in particular felt was actually her preferred ending to the game.

We did ask our participants what types of moral choices they usually made when playing such games on their own, and Miranda in particular and Emiko to some extent favored being evil, particularly if the game narrative encouraged such a stance. Emiko further explained, "I tend to be a lot meaner in games than he [Michael] is" because as she put it "Michael tends to always want to see himself and his actions in the game as heroic." On his own, Michael prefers to play games that do not regularly feature such stark choices, and so issues of ethical dilemmas rarely surface. Rose can vary her style but during initial playthroughs she will do 'what she herself would do' in the moment, unless something particularly memorable happens to break that particular style. Miranda prefers 'evil playthroughs' on her own, but felt that even through she didn't actually like the GoT series, they created an experience that was "fun, we could yell and shout and stuff." Miranda's response echoes Rose's feelings, as she also disliked the game and told us she probably would have quit playing the game on her own before its end because of her dislike for various game elements. Yet for her "having somebody there to watch or be a part of the playing while I'm playing is important to me. ... For me it's all about having someone else in the room. Playing solo is not my ideal."

These findings do suggest interesting options to explore in future research - if single players do enjoy acting as 'the hero' in games with moral dilemmas, what happens when more than one person is present? It's possible at that point that the pair (or group) defers to one person's style (as in Emiko's case) or perhaps they ramp up the action and go for the shocking, the mean, and the outrageous options instead. In those cases - which still need to be investigated further - it might be the case that 'being evil' is something that a group can more easily engage in, as players might give each other 'permission to be bad' as they are all choosing the actions, and so no one player alone is implicated as being the 'bad person.' Thus, similar to the sociality that has been found to occur around multiplayer games, single-player games can also be sources for entertainment for multiple people, as prior researchers have also found [5].

\section{Conclusions}

The research questions this case study investigated asked how known player pairs engaged in turn taking and decision-making behaviors while playing a single-player game together, and also how a narrative-driven video game played over multiple sessions impacted their experience. We found that for both pairs, turn taking was an explicitly negotiated choice, and that decision making power did not necessarily rely on who was holding the controller player pairs developed their own systems for how they made choices as well. Players also easily worked around game constraints on decision making such as timers by manually pausing the game to allow for more time. Further, the narrative and well-known franchise on which the game was based gave pairs a strong base from which to work, building themed playthroughs and systemic approaches for how to treat various characters and situations as they developed in game. They appeared at ease with one another, moving closer and apart from each other as they wished, and also sometimes scolding each other when they felt it was needed.

While other researchers have investigated social console gameplay mainly in relation to multiplayer games, and in particular physical-controller based games, this case study demonstrates that single-player games can also potentially serve as rich material for friends and couples to socialize around. Much like Voida and Greenburg, we found that pairs seemed to privilege sociality over gameplay itself, even though the game was the primary motivation to get together $[10,11]$. This was particularly evident in the case of Miranda and Rose, who reported disliking the game by the end but who wanted to keep playing mainly for the social enjoyment. Our research is also in line with findings about social television viewing, where participants seem to create unspoken rules for how and when to communicate with each other, and how to use the viewing material as 'content' for further social interactions - either as jokes, as a way to offer expertise or knowledge or as a way to comment on one's relationship(s) to others in the group.

This case study further contributes to the theory of tandem play, demonstrating how even very linear single-player games that feature little action or exploration can be entertaining material for more than one player to engage. It shows that pairs who have a prior history together approach tandem play as a 'natural' style of interaction and play, and indeed engaged in this activity regularly outside of our study conditions, according to their own reports.

The study also raises the question of how the tandem or group play situation might change how individuals approach ethical decisions during gameplay, as they are playing with another person, and not simply 'as themselves' or only as they might wish to play the game. Further research is needed to determine how ethical content and tandem play intersects. 
In conclusion, this research provides further evidence that being social in and around games can be accomplished no matter whether the chosen game is a single or a multiplayer title, and in virtual or physical space.

\section{References}

[1] N. D. Bowman, R. Weber, R. Tamborini, and J. Sherry, "Facilitating Game Play: How Others Affect Performance at and Enjoyment of Video Games," Media Psychol., vol. 16, no. 1, pp. 39-64, Jan. 2013.

[2] L. Eklund, "The Sociality of Gaming: A mixed methods approach to understanding digital gaming as a social leisure activity," Acta Universitatis Stockholmiensis, 2012.

[3] C. Pearce, Communities of play: emergent cultures in multiplayer games and virtual worlds. Cambridge, Mass: MIT Press, 2009.

[4] T. L. Taylor, Play between worlds: exploring online game culture. Cambridge, Mass: MIT Press, 2006.

[5] S. Giddings and H. Kennedy, "Little Jesuses and *@\#?-off robots: On cybernetics, aesthetics, and not being very good at Lego Star Wars," in The pleasures of computer gaming: essays on cultural history, theory and aesthetics, M. Swalwell and J. Wilson, Eds. Jefferson, NC: MacFarland, 2008, pp. 13-32.

[6] B. J. Gajadhar, Y. A. De Kort, and W. A. Ijsselsteijn, "Shared fun is doubled fun: player enjoyment as a function of social setting," in Fun and games, Springer, 2008, pp. 106-117.
[7] A. Voida and S. Greenberg, "Wii all play: the console game as a computational meeting place," in Proceedings of the SIGCHI Conference on Human Factors in Computing Systems, 2009, pp. 1559-1568.

[8] J. Downs, F. Vetere, and S. Howard, "Paraplay: Exploring playfulness around physical console gaming," in IFIP Conference on Human-Computer Interaction, 2013, pp. 682-699.

[9] J. Downs, F. Vetere, and W. Smith, "Differentiated Participation in Social Videogaming," 2015, pp. 92100.

[10] J. Juul, A casual revolution: reinventing video games and their players. Cambridge, MA: MIT Press, 2010.

[11] I. Bogost, "What are sports videogames?," in Sports Videogames, M. Consalvo, K. Mitgutsch, and A. Stein, Eds. Routledge, 2013, pp. 50-66.

[12] L. Oehlberg, N. Ducheneaut, J. D. Thornton, R. J. Moore, and E. Nickell, "Social TV: Designing for distributed, sociable television viewing," in Proc. EuroITV, 2006, vol. 2006, pp. 25-26.

[13] M. Consalvo, J. Begy, S. Ganzon, and R. ScullyBlaker, "Tandem play: Theorizing sociality in single player gameplay," presented at the International Communication Association annual conference, Fukuoka, Japan, 2016.

[14] M. Consalvo, T. Busch, and C. Jong, "Playing a Better Me: How Players Rehearse Their Ethos via Moral Choices," Games Cult., Nov. 2016.

[15] A. Lange, "Binary Choices: How Players Engage with Morality in Games," 04-Mar-2015. [Online]. Available: https://www.pluralsight.com/blog/filmgames/binary-choices-players-engage-moralitygames. [Accessed: 01-Sep-2017]. 